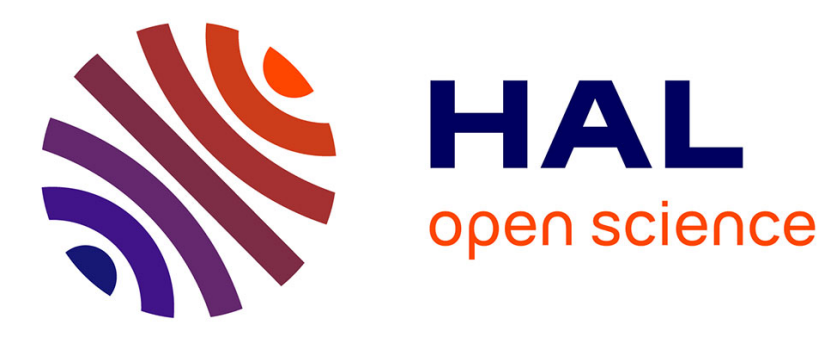

\title{
Modelling of the Injection Stretch Blow Moulding of PET Containers via a Pressure-Volume-time (PV-t) Thermodynamic Relationship
}

C. W. Tan, G.H. Menary, Y. Salomeia, C. G. Armstrong, Martine Picard, Noëlle Billon, E.M.A. Harkin-Jones, P.J. Martin, Ketan C. Maheshwari

\section{To cite this version:}

C. W. Tan, G.H. Menary, Y. Salomeia, C. G. Armstrong, Martine Picard, et al.. Modelling of the Injection Stretch Blow Moulding of PET Containers via a Pressure-Volume-time (PV-t) Thermodynamic Relationship. 11th ESAFORM Conference on Material Forming, Apr 2008, Lyon, France. pp.Pages 799-802, 10.1007/s12289-008-0296-5 . hal-00510360

HAL Id: hal-00510360

https://hal-mines-paristech.archives-ouvertes.fr/hal-00510360

Submitted on 18 Aug 2010

HAL is a multi-disciplinary open access archive for the deposit and dissemination of scientific research documents, whether they are published or not. The documents may come from teaching and research institutions in France or abroad, or from public or private research centers.
L'archive ouverte pluridisciplinaire HAL, est destinée au dépôt et à la diffusion de documents scientifiques de niveau recherche, publiés ou non, émanant des établissements d'enseignement et de recherche français ou étrangers, des laboratoires publics ou privés. 


\title{
Modelling of the Injection Stretch Blow Moulding of PET Containers via a Pressure-Volume-time (PV-t) Thermodynamic Relationship
}

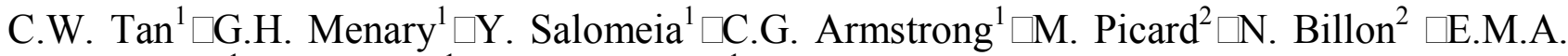 \\ Harkin-Jones $^{1} \square$ P.J. Martin ${ }^{1}$ K. Maheshwari ${ }^{1}$ \\ ${ }^{1}$ Queen's University of Belfast, \\ Ashby Building, Stranmillis Road, \\ Belfast, BT9 5AH \\ e-mail: g.menary@qub.ac.uk \\ ${ }^{2}$ Ecole de Mines de Paris \\ CEMEF - UMR CNRS 7635 \\ 0690 $\square$ Sophia Antipolis (France) \\ e-mail: Noelle.billon@ensmp.fr
}

\begin{abstract}
A 2-D isothermal finite element simulation of the injection stretch-blow moulding (ISBM) process for polyethylene terephthalate (PET) containers has been developed via the commercial finite element package ABAQUS/standard. In this work the blowing air to inflate the PET preform was modelled via two different approaches; a direct pressure input (as measured in the blowing machine) and a constant mass flow rate input (based on a Pressure-Volume-time relationship). These two methods were tested with a simplified stretch blow moulding process where a preform was blown with and without a stretch rod in free air (no mould). The results clearly show that simulation with a constant mass flow rate as input gave an excellent prediction of volume vs. time curve and preform shape evolution when compared with the direct pressure approach. In addition to this $\square$ rapid inflation of the PET preform $(\sim 0.03 \mathrm{~s})$ was found to occur in the direct pressure approach which was not observed in reality. This result reveals that the constant mass flow rate approach is more appropriate in modelling the blowing stage in ISBM process.
\end{abstract}

Key words: PET $\sqsubset$ blow moulding $\square$ material model.

\section{INTRODUCTION}

The injection stretch blow moulding (ISBM) process is the main method used to mass-produce PET bottles. Nowadays modelling techniques for the ISBM process have become increasingly important in optimising products and processes. Process modelling is used to obtain better insight into the process operation in order to identify the critical processing condition which gives a product with optimum quality. This reduces trial and error experimentation $\square$ reduces new product turnaround time and can be used to reduce bottle weights by determining the optimum distribution of material in the bottle for mechanical and barrier performance.

This paper takes a step back from the development of ISBM simulation and aims to investigate the inflation of preform in free air. This is somewhat simpler to simulate than the real process as modelling contact with the mould and stretch rod is not required. The free blow and free stretch blow experiments also offer the opportunity to measure the process in much more detail than that can be found when inflating a preform inside a mould.

\section{EXPERIMENTAL WORK}

Free blow experiments were carried out on an instrumented prototype developed in CEMEF using marked preforms according to protocols defined in previous studies [12]. TF9 grade material (IV=0.73) was supplied from Tergal Fibre for the manufacture of an $18.5 \mathrm{~g}$ PET preform. The geometry of the PET preform used in the current study is given in Fig. 1 below.

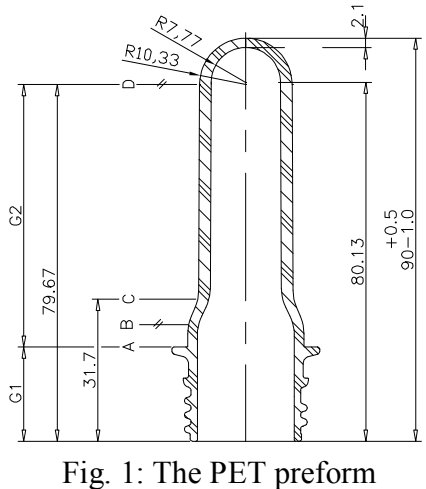

The outer surface temperatures of the $18.5 \mathrm{~g}$ preform measured just before blowing commenced is shown in Fig. 2. The data was captured using a pyrometer. 


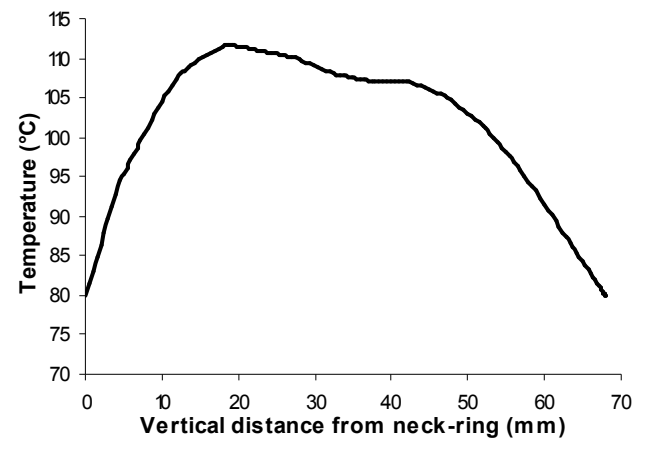

Fig. 2: Preform temperature distribution

Once the preform has been heated to a pre-defined temperature $\square$ it was transferred to a stretch-blow machine $\square$ where it was subjected to a stretch blowing process (free blow experiment involves only blowing stage). Figs. 4 and 5a show the evolution of preform shape and the corresponding pressurevolume vs. time curve for free blow experiment whilst Figs. 6 and 7a show the evolution of preform shape and the corresponding pressure-volume vs. time curve for free stretch blow experiment. A key point to note is the rapid inflation of the preform coinciding with a rapid dip in the pressure. Additional experiments showed that this curve varied with different preform temperature profiles and magnitude of applied nominal pressure.

\section{FINITE ELEMENT SIMULATION}

\subsection{Simulation Set Up}

2D free blow and free-stretch blow simulations were developed by using the commercial finite element (FE) package ABAQUS/standard version 6.5. The preform geometries have a common symmetrical loading axis about the middle plane. Thus it was decided to model the preform by using the deformable axisymmetric membrane elements (element type 'MAX1' in ABAQUS element library) in the FE analysis. The thickness and temperature of the PET preform were defined through the use of nodal thickness and nodal temperature options along the membrane profile. Since the steel stretch rod is much stiffer than the PET preform $\square$ it was modelled using axisymmetric rigid elements (element type 'RAX2' in ABAQUS element library).

The stretch rod displacement and pressure profile (up stream line pressure) for the free blow trials were supplied by CEMEF. The blowing stage of the initial simulations is based on the supplied data where the measured pressure profile was applied directly into the simulation. However $\square$ it has been proved previously that the internal pressure measured inside the preform is significantly different to the up stream line pressure [3]. It was found that the line pressure is not an input variable $\square$ but in fact is an output variable in the bottle blowing process based on the supply pressure $\square$ preform temperature and preform shape. Thus $\square$ an alternative method called the fluid flow method (supply the PET perform with a flow rate of air form which the pressure is subsequently calculated based on ideal gas law) was used to model the blowing air in the two investigated processes. In this simulation the numerical coding of an Abaqus UMAT of the Buckley-Jones-Adams [456] was used in modelling the constitutive behaviour of PET. The material constants for the studied PET material (TF9 grade) were established through systematic fitting of the experimental data (simultaneous equal biaxial testing) to the model [7].

\subsection{Mass Flow Rate Evaluation}

The mass flow rate of air was calculated based on the pressure and volume vs. time curves measured during the free blow trials (Fig 3). The curve is divided in to two regions Zone $\mathrm{A}$ has transient flow in constant volume and Zone B has steady flow with changing volume. Equations 1 and 2 were then used to calculate the mass flow rate in Zone A and Zone $\mathrm{B}$ respectively. It should be noted that since the ratio between the supply pressure $(0.7 \mathrm{MPa})$ and the measured pressure in the preform is greater than or less than 1.9 then it is reasonable to assume the flow is "choked" and therefore constant [8]. Based on the calculations $\square$ an average mass flow rate of $\underline{0.014 \mathrm{~kg} / \mathrm{s}}$ is used in the current simulations.

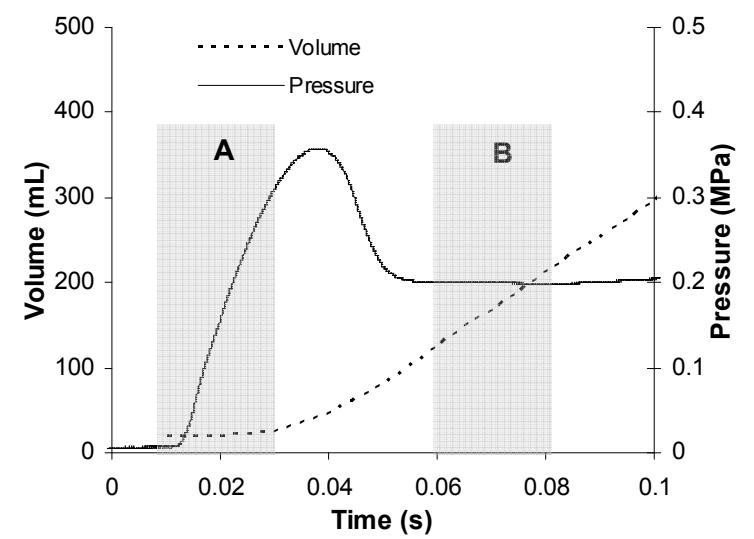

Fig. 3: Mass flow rate calculation from pressure vs. time curve

$\dot{m}=\frac{d P}{d t}\left(\frac{V}{C_{p} T_{0}(\gamma-1}\right) \ldots \ldots$ Eqn (1) $\quad \dot{m}=\rho \cdot \frac{d V}{d t} \ldots \ldots$. Eqn (2)

Where $P$ is the pressure $\square$ is the time $\square V$ is the volume $\square C_{p}$ is the specific heat $\square T_{0}$ is the gas temperature $\square \gamma$ is the specific heat ratio and $\rho$ is the gas density. 


\section{RESULTS AND DISCUSSION}

\section{$\square 1$ Free Blow Simulation}

Fig. 4 shows the pressure and volume against time predicted by the simulation compared with that measured by experiment. Two simulated results are presented; one is using direct pressure as input and the other is via the fluid flow method i.e. a constant mass flow rate of air of $0.014 \mathrm{~kg} / \mathrm{sec}$ is supplied. Comparison of the preform shape evolution between the experimental and simulated results is shown in Fig. 5.

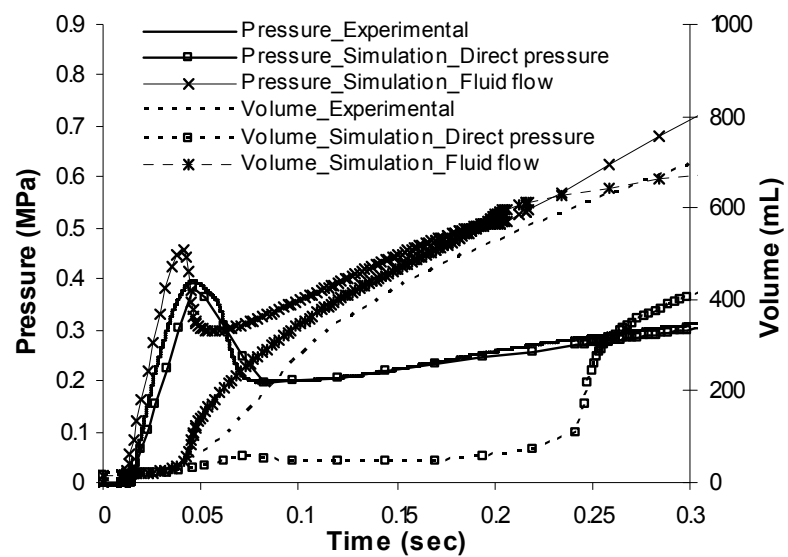

Fig. 4: Pressure-volume-time curve for free blow simulation using direct pressure and mass flow rate inputs

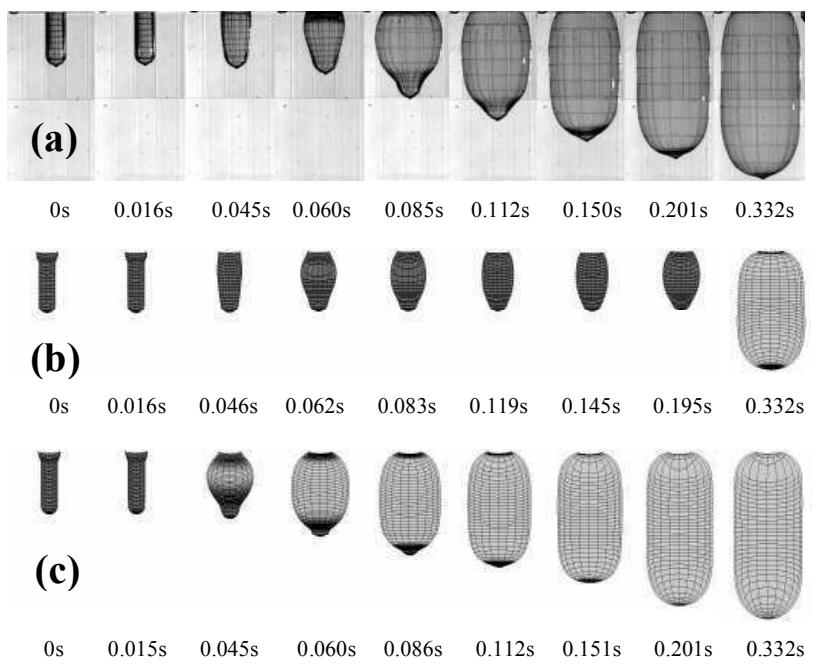

Fig. 5: Preform shape evolution. Experiment (a) vs. simulation via direct pressure (b) and mass flow rate input (c).

As can be seen from Fig. 4 a poor volume-time curve was obtained by using direct pressure input method with two major discrepancies observed; rapid inflation of the preform occurs over 0.03 seconds and the inflation of preform occurs at much later time in the simulation ( 0.23 seconds). Using the mass flow rate approach $\square$ the inflation of preform occurs at almost similar time as the experimental result. Also $\square$ the volume increases gradually just like experimental measurement. This indicates the constant mass flow rate method is the most appropriate method to model the pressure input. It should be noted that the peak pressure predicted by the mass flow rate approach is found higher than the experimental result. (0.46 vs. $0.4 \mathrm{Mpa}$ ). Also $\square$ the subsequent pressure after the pressure dip is found higher than the experimental result. This needs further investigation but because of the sensitivity of the pressure to the material parameters and the fact the point of bubble inflation is essentially a bifurification it is unlikely that accurate predictions will be achievable. However the results compare qualitatively.

It can been seen from Fig. 5 that the preform shape evolution of the simulated result using direct pressure input does not correspond to the experimental result. Inflation of the preform is found to occur at a later stage. The blowing stage of the simulated result using constant mass flow rate method was found to closely match the experimental results. However the experimental result was found to lag behind the simulation result by approximately $20 \mathrm{~ms}$. Considering the assumptions for calculation of mass flow rate and the material properties it is a reasonable prediction.

\section{$\square 2$ Free Stretch Blow Simulation}

The free blow trials were also performed with the use of a stretch rod making them more representative of the industrial ISBM process. Fig. 6 shows the pressure-volume against time for both the experiment and the simulated results. Comparison of the preform shape evolution is also given in Fig. 7. All simulations were carried out using the constant mass flow rate of $0.014 \mathrm{Kg} / \mathrm{s}$ calculated previously.

A similar result is observed in Fig. 6 as seen in the free blow simulation where the direct pressure input gave a poor volume-time curve when compared with that measured experimentally with the two major discrepancies as discussed previously. Excellent volume-time curve is obtained in the free stretch blow simulation using the constant mass flow rate method. Similar to the free blow simulation $\square$ higher pressure is predicted by the simulation. This can be rationalised by considering the exclusion of temperature gradient through the thickness direction in the current simulation (up to $10^{\circ} \mathrm{C}$ hotter in the inner surface of the preform). This causes stiffer material behaviour in the simulation which results in higher predicted pressure. 
The preform shape evolution of the simulated result using constant mass flow rate method was found to closely match the experimental results (Fig. 7). The bubble initiates and inflates at almost the same time $(0.038 \mathrm{sec})$ for both the simulated and experimental result. Again we observed a poor prediction using the direct pressure method.

The nodal displacement (ND) of three locations (L2 $\square$ L4 $\square$ and L7) in axial direction is also recorded. The comparison between the experimental and simulated result using constant mass flow rate method are shown in Fig. 8. The predicted nodal displacement result in the axial direction was found to closely match the experimental result particularly at location L7. This result validates the material model and characterised constants used in the current simulation.

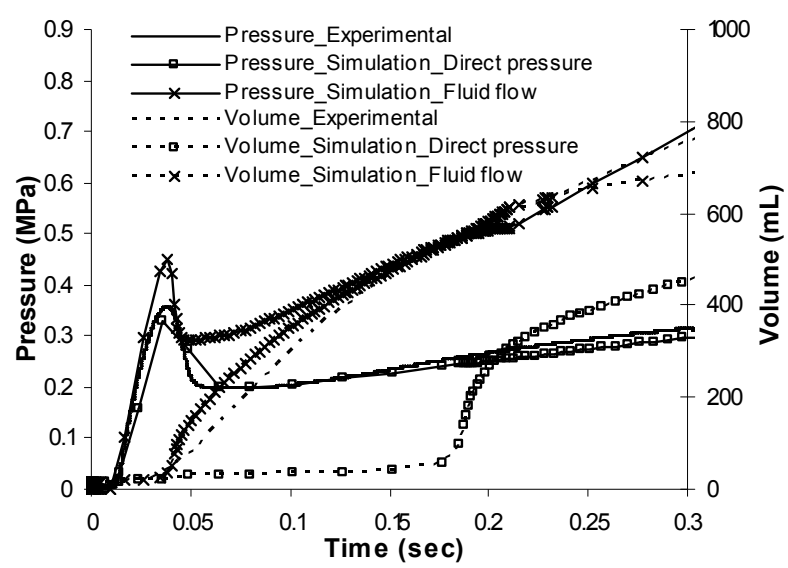

Fig. 6: Pressure-volume-time curve for free stretch blow simulation using direct pressure and mass flow rate inputs

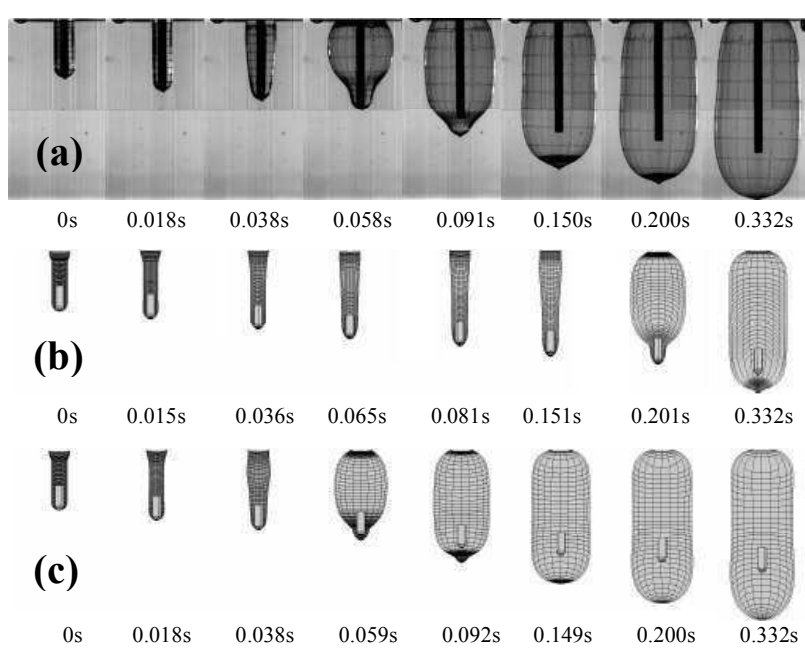

Fig. 7: Preform shape evolution. Experiment (a) vs. simulation via direct pressure (b) and mass flow rate inputs(c).

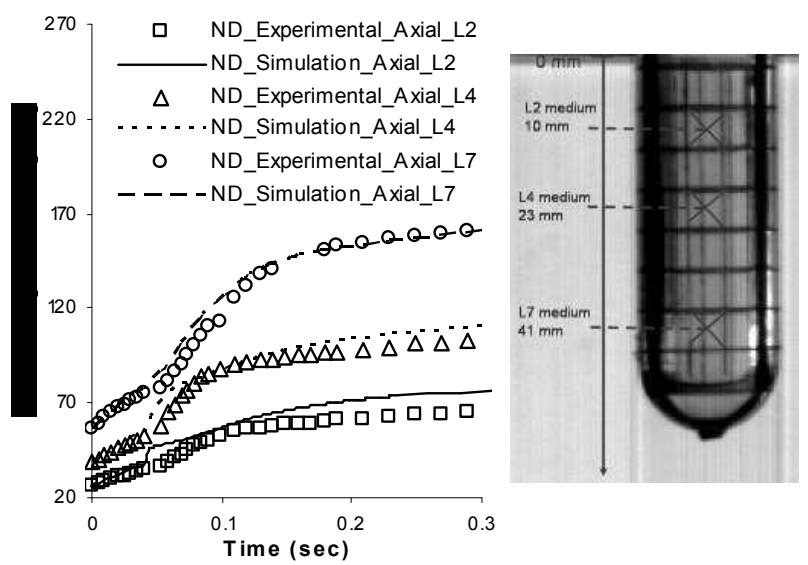

Fig. 8: Nodal displacement location for free-stretch blow simulation using constant mass flow rate input

\section{CONCLUSIONS}

Excellent volume vs. time curve and preform evolution profile are obtained in both the free blow and free stretch blow simulations only in the case when constant mass flow rate is used to model the blowing air in the simulation. This indicates that applying the pressure via a mass flow rate of air is the most appropriate method to model the pressure inside the preform. Considering assumptions for temperature $\square$ experimental error and flow rate calculations correlation between experiment and simulation for both free blow and free stretch blow is excellent. This validates the simulation development $\square$ mass flow rate calculation $\square$ material model and the characterised constants for the free blow and free-stretch blow trials.

\section{REFERENCES}

1) Gorlier E. PhD Thesis Ecole des Mines de Paris (France) $\square$ 2001.

2) Gorlier E. $\square$ Haudin J.M. $\square$ Agassant J.F. $\square$ Lepage J.L. $\square$ Perez G. $\square$ Darras D. $\square$ Billon N. $\square$ 4th International ESAFORM Conference on Material Forming $2001 \square$ Liege $\square$ Belgium.

3) Menary G.H. $\square$ Tan C.W. $\square$ Picard M. Billon N. $\square$ Armstrong C.G. Harkin-Jones E.M.A. $\square$ 10th International ESAFORM Conference on Material Forming 2007 $\square$ April 18-20 $\square$ Zaragoza $\triangle$ Spain.

4) Buckley C.P. $\square$ Jones D.C. $\square$ Polymer $\square 6 \square \square 7 \square 3301 \square 995$.

5) Buckley C.P. $\square$ Jones D.C. $\square$ Jones D.P. $\square$ Polymer $\square 37 \square 12 \square$ $2403 \square 996$.

6) Adams A.M. $\square$ Buckley C.P. $\square$ Jones D.P. $\square$ Polymer $\square 41 \square 771 \square$ 2000.

7) Menary G.H. $\square$ Tan C.W. $\square$ Armstrong C.G. $\square$ Harkin-Jones E.M.A. $\square$ 9th International ESAFORM Conference on Material Forming 2006 $\square$ April 26-28 Glasgow $\square$ U.K.

8) Cengel Y.A. $\square$ Boles M.A. $\square$ "Thermodynamics" $\square 6^{\text {th }}$ Edition $\square$ McGraw-Hill Publication 2007. 